\title{
Monitoring Progressive Multiple Sclerosis with Novel Imaging Techniques
}

\author{
Maria Petracca - Monica Margoni - Giulia Bommarito • \\ Matilde Inglese
}

Received: May 14, 2018 / Published online: June 28, 2018

(C) The Author(s) 2018

\begin{abstract}
Imaging markers for monitoring disease progression in progressive multiple sclerosis (PMS) are scarce, thereby limiting the possibility to monitor disease evolution and to test effective treatments in clinical trials. Advanced imaging techniques that have the advantage of metrics with increased sensitivity to short-term tissue changes and increased specificity to the structural abnormalities characteristic of PMS have
\end{abstract}

Enhanced digital content To view enhanced digital content for this article go to https://doi.org/10.6084/ m9.figshare.6490532.

M. Petracca $\cdot$ M. Margoni

Department of Neurology, Icahn School of Medicine at Mount Sinai, New York, NY, USA

\section{Margoni}

Multiple Sclerosis Centre, Department of Neurosciences DNS, University Hospital, University of Padua, Padua, Italy

\section{G. Bommarito $\cdot$ M. Inglese}

Department of Neuroscience, Rehabilitation, Genetics and Maternal and Perinatal Sciences, University of Genoa, Genoa, Italy

\section{Inglese ( $\square)$}

Departments of Neurology, Radiology and

Neuroscience, Icahn School of Medicine at Mount

Sinai, New York, NY, USA

e-mail: matilde.inglese@mssm.edu recently been applied in clinical trials of PMS. In this review, we (1) provide an overview of the pathological features of PMS, (2) summarize the findings of research and clinical trials conducted in PMS which have applied conventional and advanced magnetic resonance imaging techniques and (3) discuss recent advancements and future perspectives in monitoring PMS with imaging techniques.

Keywords: Advanced imaging; Biomarker; Clinical trials; Progressive multiple sclerosis

\section{INTRODUCTION}

Conventional brain imaging is increasingly used to support clinicians in diagnosing and monitoring the progression of multiple sclerosis (MS) [1]. Nevertheless, the correlation between a patient's clinical manifestation and conventional magnetic resonance imaging (MRI) measures is often weak, especially in patients with progressive MS (PMS).

The 2013 revised classification of the clinical phenotypes and disease course of MS categorizes the disease as active or not (based on recent clinical relapse or MRI lesion activity) and progressive or not (based on clinical assessment of disability), considering primary progressive MS (PP-MS) and secondary 
progressive MS (SP-MS) to be different phenotypes in a unique spectrum [2].

From a pathophysiologic standpoint, the progressive stage of MS is characterized by the segregation of inflammatory activity within the brain compartment, where B cells play a dominant role and lymphoid follicle-like structures form in the subarachnoid space. Follicle-like structures are observed in patients with SP-MS but are uncommon in those with PP-MS, suggesting that these two phenotypes have different underlying pathogenetic mechanisms [3]. However, despite the absence of follicle-like structures in the latter, meningeal inflammation and cortical demyelination are well represented in PP-MS patients also [3]. In addition to compartmentalized inflammation, neurodegeneration is a major feature of patients with PMS, even though the temporal relationship between the two pathological processes remains a matter of debate $[4,5]$. At the progressive stages of the disease, neurodegeneration seems to occur even in the absence of an overt inflammatory process, affecting a system already worn out and lacking a functional reserve [6]. Unlike in relapsing-remitting MS (RR-MS), imaging or biological markers of disease progression and response to treatment are scarce in PMS; consequently, there are only limited possibilities to assess the efficacy of treatments in clinical trials. Advanced imaging techniques can provide important information to improve our knowledge of MS pathophysiology and to identify reliable markers of disease progression and treatment efficacy. Indeed, among the advanced imaging techniques, a few have been applied in clinical trials in recent years, in the attempt to increase their sensitivity and identify short-term changes and treatment response utilizing metrics that are more specific to the structural abnormalities characteristic of PMS [7].

In this review, we first provide an overview of the pathological features of PMS, then we summarize the findings of research and clinical trials conducted in PMS which have applied conventional and advanced MRI techniques according to anatomical compartment (i.e. white matter [WM], cortex, deep grey matter [DGM], cerebellum, spinal cord). Finally, we discuss recent advancements and future perspectives in monitoring PMS with imaging techniques. This article is based on previously conducted studies and does not contain any studies with human participants or animals performed by any of the authors.

\section{WHITE MATTER DAMAGE}

\section{Pathological Features}

The pathological abnormalities occurring in the brain WM of patients with RR-MS or PMS are similar. Both the formation and/or expansion of focal lesions of primary demyelination in the $\mathrm{WM}$ and the neurodegeneration in plaques and normal-appearing white matter (NAWM) are driven by inflammation and sustained by the presence of $\mathrm{B}$ and $\mathrm{T}$ lymphocytes [6]. Focal lesions are characterized by the formation of a profound astrocytic scar and a variable extent of axonal loss and remyelination, with the prominent feature (i.e. active inflammation, demyelination, neurodegeneration) changing as the disease evolves [8]. In early MS, the pathological picture is characterized by the formation of new WM lesions, and many of the plaques are in the active stage of demyelination. In contrast, in PMS new active plaques are rare, but many of the pre-existing lesions show a slow expansion, as revealed by the presence of a rim of activated microglia at the lesion border associated to macrophages with inclusions of myelin degradation products [9].

NAWM shows a profound diffuse pathology, which consists of small perivenous inflammatory infiltrates surrounded by small rims of demyelination, diffuse astrocytic gliosis, diffuse microglia activation and axonal degeneration [10].

RR-MS and PMS show similar inflammation patterns, although the global extent of lymphocytic inflammation is higher in RR-MS in comparison to PMS. Indeed, in RR-MS the lymphocytic infiltration is associated with blood-barrier disruption, while in the progressive stage, inflammation is at least partly 
compartmentalized in the brain behind an intact blood-brain barrier [11].

\section{Conventional Imaging}

White matter lesions are usually identified on T2-weighted (T2W) and fluid-attenuated inversion recovery (FLAIR) sequences. Lesions seen on T2W scans are not pathologically specific and may show different degrees of inflammation, axonal loss, demyelination [12] and remyelination [13]. Thus, a cross-sectional evaluation of a T2W lesion is a poor marker of the underlying pathological substrate. A subset of lesions seen on T2W and FLAIR scans can be detected on T1-weighted (T1W) scans; these are termed "black holes" due to their hypointensity relative to the surrounding WM and are thought to represent lesions with greater myelin and axonal loss [14]. As persistent back holes are regarded as a measure of tissue disruption, a reduction in T1-hypointense lesions accrual has been previously used in clinical trials as an index of reduced acute tissue damage [15].

In PP-MS, the low level of T2-visible lesion load and gadolinium-enhancing lesions is in contrast with the severity of the clinical features and the steady progression of the disease [16]. MR-detectable inflammation occurs more commonly in early PP-MS (during the first 5 years from onset) than later in the course of the disease [17]; however, this has been shown to have only a minimal impact on the accumulation of disability over the subsequent 5 years [18]. Similarly, the number of T2-visible brain lesions at baseline does not seem to play a role on the rate of clinical progression in the subsequent 15 years in these patients [19]. In one study in patients with SP-MS, the number and volume of lesions at baseline showed a number of correlations with 20 years of disability at the 20-year follow-up. The annual rate of WM lesion accumulation was over threefold greater in those developing SP-MS by 20 years than in patients who did not convert, and this difference became statistically significant after 5 years [20].

\section{Advanced MRI Techniques}

\section{Magnetization Transfer imaging}

Magnetization transfer (MT) MRI provides an index, called the MT ratio (MTR), whose values reflect the efficiency of the magnetization exchange between protons in tissue water and those bound to the macromolecules. Post-mortem studies $[13,21]$ have shown that marked reductions in MTR values in MS lesions and NAWM are strongly correlated with the percentage of residual axons and the degree of demyelination and that MTR values of remyelinated lesions are higher than those of the NAWM.

MTR values of T2-visible lesions are decreased relative to those of the NAWM in PPMS patients, and MTR values of the NAWM are decreased relative to those of the WM of healthy controls [22, 23]. Damage to the NAWM is more pronounced in SP-MS and PP-MS patients than in other clinical phenotypes [24, 25], but it does not differ between patients with the two progressive forms of the disease [26]. Longitudinal studies suggest that MT MRI has the potential to be a good biomarker of progression in PP-MS: in patients with early PP-MS, lower NAWM MTR values at baseline predict a more severe deterioration of disability over 1 [27] and 3 years [28]. In view of these findings, MTR has been included in several clinical trials of PMS [29-31]. In an open-label phase $2 \mathrm{~A}$ study on the use of natalizumab for treating patients with SP-MS, MTR was used to assess the tissue integrity on a macromolecular level. In the treated patients, MTR values increased in NAWM, indicating an increased integrity of myelin and neurons or reduced microglial activation [31]. In a study on the use of autologous mesenchymal stem cells in SP-MS patients, the MTR increased after treatment, but these changes were not statistically significant [29]. In a longitudinal study in SP-MS patients treated with interferon (IFN) beta- $1 b$, there was a decrease in the average brain MTR values from baseline to month 24 and month 36 . These changes were significant for the placebo group at both time points and for the IFN beta-1b group at month 24 only, with no significant treatment effect [32]. Another longitudinal study investigated the role of lamotrigine in SP-MS and demonstrated 
a decrease in the NAWM MTR in the treated patients at baseline, but no differences in MTR change between the two groups at follow-up [33]. In summary, MT MRI provides information on the changes which occur in both NAWM and WM lesions, and it is sensitive to disease changes over time [34]. Furthermore, values derived from MT MRI are reproducible [35] and relatively cost-effective.

\section{Diffusion Tensor Imaging}

Diffusion tensor imaging (DTI) is a diffusionweighted MRI method that measures brain tissue microstructure exploiting the properties of water diffusion. Using the measures obtained with this method, it is possible to calculate the magnitude of diffusion, reflected by mean diffusivity (MD), diffusion anisotropy, which is a measure of tissue organization, generally expressed as fractional anisotropy (FA), axial diffusivity (AD) and radial diffusivity (RD), with the latter two items being measures of axonal integrity and myelin integrity, respectively (Fig. 1) [36].

The FA within T2 lesions is usually decreased and the MD usually increased in comparison with those of the surrounding NAWM [37]. An overlap between MD and FA maps and T2 lesion distribution has been demonstrated in most MS phenotypes [38], with the exception of PP-MS patients, in whom there is a discrepancy between regional WM diffusivity changes and
T2-visible focal lesions [39]. The absence of any overlap in PP-MS between FA maps and T2 lesions [38] support the hypothesis that axonal damage and T2 lesions are partially independent.

WM diffusion abnormalities are more pronounced in patients with SP-MS than in those with RR-MS [38, 40]. The greater increase in diffusivity in SP-MS than in other phenotypes is presumably caused by a combination of axonal loss and tissue destruction processes with inflammatory events [40]. The high degree of axonal degeneration in such patients is confirmed by the widespread decrease in FA, not only within lesions but also in the NAWM [38].

Although widespread diffusivity changes have been detected in patients with PP-MS in comparison with healthy controls, with increases in $\mathrm{MD}, \mathrm{RD}$ and $\mathrm{AD}$ and decreases in FA $[38,41]$, the NAWM is affected to a lesser degree in PP-MS patients than in SP-MS patients $[38$, 42], probably owing to the more pronounced inflammation present in SP-MS than in PP-MS. Diffusion-based MRI parameters have been used to assess the role of natalizumab in SP-MS, with the results revealing a significant increase in FA in the NAWM and in AD and RD in T2 lesions after 60 weeks of treatment [31].

DTI measures have also been applied in monitoring tissue integrity in ongoing clinical trials evaluating the efficacy of ibudilast and fluoxetine in progressive MS [30, 43].

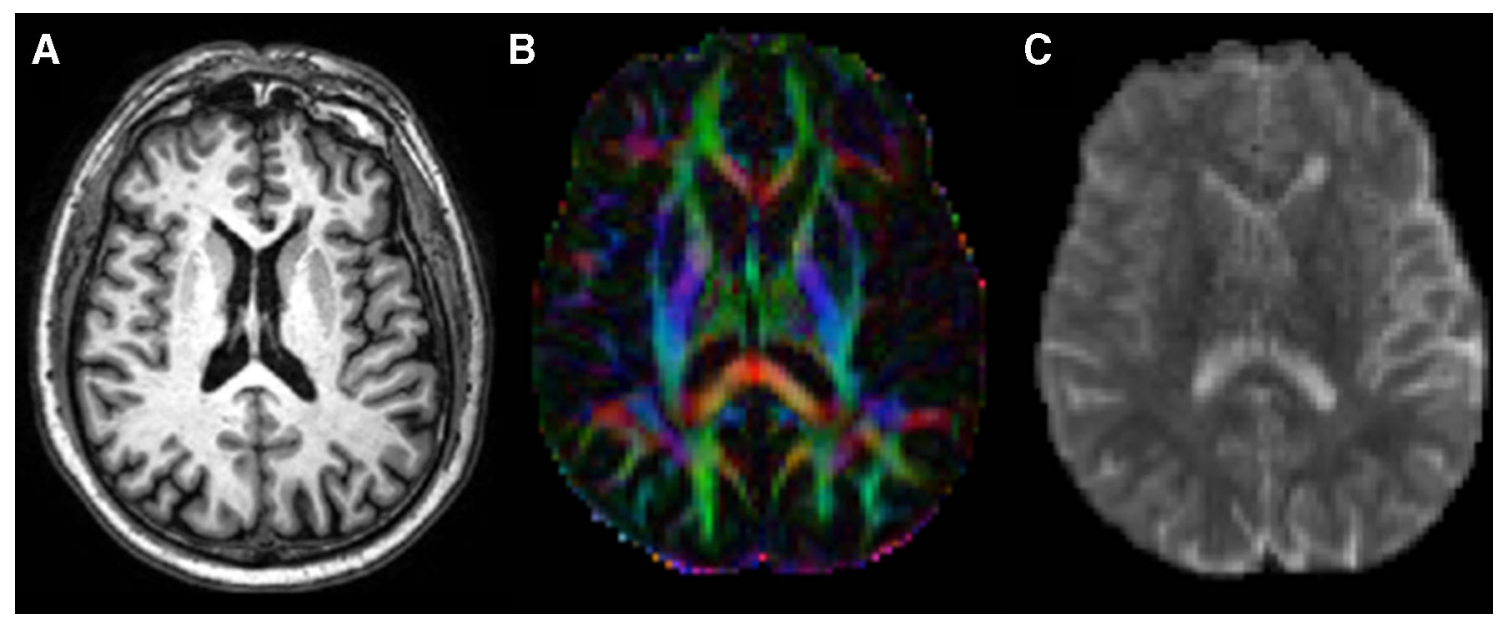

Fig. 1 Three-dimensional T1-weighted image (a) and representative maps of fractional anisotropy (b) and mean diffusivity (c) from a patient with progressive multiple sclerosis 
However, although sensitive to changes in tissue integrity, classical DTI metrics may lack pathological specificity. Additionally, the sample size estimates for diffusion-based metrics are highly variable and depend on the specific metric and the area of the brain [44].

\section{Proton Magnetic Resonance Spectroscopy}

Proton magnetic resonance spectroscopy $\left({ }^{1} \mathrm{H}\right.$ MRS) can quantify the brain levels of several metabolites [45]. The most commonly measured neurometabolite is total $\mathrm{N}$-acetyl-aspartate (NAA), a marker of axonal loss and metabolic dysfunction [46]. NAA levels are significantly decreased in the NAWM of PP-MS patients relative to the WM of healthy controls, but comparisons of ${ }^{1} \mathrm{H}$-MRS findings between patients with PP-MS and those with other disease phenotypes does not show significant between-group differences in terms of lesional and NAWM levels of NAA $[47,48]$. The ratio between NAA and other metabolites has been used in a clinical trial to compare glatiramer acetate-treated and placebo-treated PP-MS patients; no differences in the NAWM and WM lesions of the two groups [49].

\section{Positron Emission Tomography}

Positron emission tomography (PET) is a quantitative imaging technique which investigates cellular and molecular processes in vivo using a positron-emitting radionuclide (tracer). Many radiotracers can be used in PET, including the selective radioligand ${ }^{11} \mathrm{C}$ PK11195 that expresses the concentration of translocator protein (TSPO) [50], a protein that is upregulated in activated microglia [51]. Studies on PMS have demonstrated an increase in TSPO uptake in the NAWM that appears to be related to clinical severity and patient age [52]. TSPO binding is significantly increased in the NAWM of SP-MS patients in comparison to the NAWM of healthy controls, with this increase being a demonstration of persisting inflammatory activity [53]. To date, no large MS clinical trials have included PET, reflecting its relatively invasive nature and high costs.

\section{CORTICAL DAMAGE}

\section{Pathological Features}

Although no pathognomonic MRI parameter has been identified in PMS, some of the characteristics highlighted by histopathology studies, such as higher grey matter (GM) atrophy, larger cortical demyelination and meningeal inflammatory aggregates, can be imaged with specific advanced MRI techniques. Inflammation, the prominent feature of MS in the early stages, persists in PMS but becomes compartmentalized within the central nervous system, behind an intact blood-brain barrier. Although a mild disruption of the blood-brain barrier has been reported in the context of chronic lesions, inflammatory infiltrates displaying structural features of lymphatic follicles tend to localize in the connective tissue spaces of the brain, such as the meninges and the large Virchow-Robin spaces [54]. Leptomeningeal infiltrates are often associated with cortical lesions, which are most abundant in the progressive stage of MS and involve preferentially the subpial cortical layers [10]. Beyond focal lesions, demyelination extensively involves GM in PMS, and the cortex is regarded as a primary site of neurodegeneration as brain atrophy in PMS is mainly related to extensive loss of synapses and the focal loss of neuronal bodies in the cortex $[55,56]$, rather than WM loss [57].

\section{Advanced MRI Techniques}

\section{Post-Contrast FLAIR}

Leptomeningeal inflammatory infiltrates can be visualized with delayed high-resolution postcontrast T2 FLAIR MRI [58, 59]. Such infiltrates are closely associated with subpial demyelination and cortical atrophy, show a high prevalence in progressive patients (33\% in SP-MS vs. $19 \%$ in RR-MS) and tend to remain stable over time [58-60]. They are not exclusively observed in MS, but their relationship with cortical atrophy and cortical lesions appears to be highly specific [61]. 


\section{Double Inversion Recovery and Phase-Sensitive Inversion Recovery}

Grey matter demyelination is more frequent in patients with PMS than in those with RR-MS [10]. Cortical lesions can be visualized, at 1.5 and 3.0 Tesla, with specific sequences that enhance the contrast between normal-appearing GM and focal GM lesions. Both double inversion recovery (DIR) and phase-sensitive inversion recovery (PSIR) can be used to detect MS cortical pathology, with PSIR showing the higher sensitivity [62]. At an ultra-high MR field (7 Tesla), cortical lesions can be imaged through FLASH-T2*, and lesions so identified show a strong correlation with disability status [63]. Although no clinical trial has applied cortical lesion quantification in PMS, suppression of cortical pathology (i.e. cortical lesion accumulation and cortical atrophy progression) has been reported in a longitudinal study exploring the impact of natalizumab antinflammatory activity in RR-MS [64].

\section{Magnetization Transfer Ratio}

Demyelination involves not only WM but also cortical GM, with myelin repair appearing to be more efficient in lesions in the latter than in those in the former [65]. MTR maps are sensitive to changes in myelin content in all brain tissues [66], and although the MTR signal can be influenced by factors such as axonal loss, inflammation and edema, their impact is less pronounced in the cortex [67], supporting the suitability of MTR for investigating myelin loss and repair in cortical areas. The MTR shows a high correlation with myelin and axonal content in post-mortem MS samples [21, 68] and with NAA, which is a spectroscopic marker of neuroaxonal content in vivo [69]; as such, it is particularly promising as imaging marker in PMS where axonal loss and GM damage are prominent. Normal-appearing GM (NAGM) demyelination, as measured using the MTR, has been chosen as the imaging outcome in several trials conducted in PMS and found to demonstrate a good correlation with clinical disability and sensitivity to treatment effects [27, 31, 33, 70]. Unfortunately, despite showing a consistently good correlation with disability metrics, responsiveness of the MTR to change (i.e. the longitudinal correlation of MTR measures with sustained disability), which was specifically evaluated in a randomized placebo controlled trial of lamotrigine in SP-MS, seems to be limited [33].

\section{Diffusion Tensor Imaging}

Different degrees of NAGM damage can be identified via diffusion-weighted imaging and DTI in different MS phenotypes, with more severe changes reported in PMS that RR-MS $[42,71]$. In patients with progressive disease, DTI-derived parameters are also able to detect significant worsening over 1 year of follow-up, with NAGM damage occurring independently from T2 lesions and brain atrophy accrual $[42,72]$. DTI-derived metrics are sensitive to change over time [31] and reproducible across different centers [73, 74]. However, the adequacy of these metrics in describing the complexity of brain tissue has been questioned in recent years, as the DTI model assumes that each voxel contains a single tissue compartment with Gaussian diffusion and that its metrics are affected similarly by changes in microstructure and changes in directional organization. As a consequence, multi-compartment models have been developed to take into account the complexity of brain tissue microstructure [75] in an attempt to better characterize pathophysiological processes underlying tissue damage.

\section{$T 2 *$}

$\mathrm{T} 2 *$ relaxation time is a quantitative measure of myelin and iron content [76]. In cortical lesions, correlation studies of histopathological and MR data have shown that demyelination and iron loss induce an increase in $\mathrm{T} 2{ }^{*}$ relaxation time [77, 78], while iron accumulation results in a shorter $\mathrm{T} 2 *$ [79]. At ultra-high field, surface-based mapping of quantitative $\mathrm{T} 2 *$ is a non-invasive tool to assess in vivo the architecture of the cortex, as it offers the possibility to conduct a laminar analysis as a function of the cortical depth [80]. The application of this method has shown a gradient of cortical pathology, with superficial cortical layers involved in early stages and deeper cortical 
layers involved in later disease stages, thereby supporting the presence of a pathological mechanism driven from the pial surface [81].

\section{Proton Magnetic Resonance Spectroscopy}

${ }^{1} \mathrm{H}-\mathrm{MRS}$ allows the quantification of NAA, which is synthesized by neuronal mitochondria, offering the possibility to monitor neuroaxonal dysfunction and quantify diffuse GM involvement. Several studies have demonstrated a decrease in NAA in the cortical GM of patients with PMS [41, 82], but the clinical translation of ${ }^{1} \mathrm{H}$-MRS-derived parameters is hampered by the negative results of several longitudinal studies $[49,83]$.

\section{Positron Emission Tomography}

Positron emission tomography with TSPO radioligands allow in vivo imaging of microglial activation and has proven the persistence of widespread inflammation in cortex and cortical lesions in PMS [52]. Such microglial activation seems to have a pathological role and to be clinically meaningful, as it is related to cortical thinning and clinical disability [52].

\section{T1-Derived Measures of Atrophy}

Quantitative estimation of brain atrophy, based on $\mathrm{T} 1 \mathrm{~W}$ sequences, suggests that progressive loss of brain volume is driven by GM atrophy [84]. Global cortical atrophy is more prominent in PMS than in the other disease phenotypes, and it is associated with both the motor and cognitive components of clinical disability in cross-sectional and longitudinal studies $[20,57,84]$. More recently, a regional analysis of cortical atrophy rate has demonstrated that atrophy does not follow the same spatiotemporal pattern in all MS phenotypes and that temporal cortical GM shows accelerated atrophy in SP forms [85]. Sample sizes for brain atrophy outcomes in PMS clinical trials have demonstrated that longitudinal estimation of brain volume changes through a registrationbased method has a higher sensitivity than segmentation-based techniques, highlighting the fact that the sensitivity of imaging biomarkers is strictly dependent on the selected processing pipeline [86]. Brain atrophy and GM atrophy have been used as primary outcomes in several phase 2 and phase 3 clinical trials in PMS [30, 87-89]; both were found to show a good effect size in the treatment arm in comparison to the placebo arm. Conversely, the application of cortical atrophy measurement (i.e. cortical thickness) in clinical trials is limited by the computational efforts required for its estimation. Taking into account that regional volumes show higher sensitivity to change over time than whole brain volume and that atrophy development follows different patterns across phenotypes, future trials should focus on the selection of sensitive and specific outcome measures that consider the characteristics of the target population.

\section{SPINAL CORD}

\section{Pathological Features}

In MS patients, spinal cord lesions are frequently detected in the upper cervical cord, but diffuse abnormalities of the spinal cord can also be observed that are associated with demyelination and axonal loss. Not only WM demyelination, which involves in particular the cervical tract, but also extensive demyelination of the spinal cord GM has been detected, in post-mortem studies [90]. Performing a postmortem in situ spinal cord MRI, Bergers et al. found that signal intensity on proton densityweighted images inversely correlated with histopathologically detected myelination in PMS [91]. In another study involving 19 patients with either SP-MS or PP-MS, a good correlation between the MR signal and demyelination based on histopathology was reported [92]. Moreover, a reduction in axonal density both at the level of the plaque and the NAWM has been described in SP patients [93]. Neuronal loss is detected primarily in the local GM plaques and interneurons in both myelinated and demyelinated areas [95]. However, myelin content and axonal loss can occur independently, and MR signal intensity abnormalities strongly correlate with demyelination [94]. There are no differences between PP-MS and SP-MS patients in terms of the presence of 
inflammatory demyelination and the capacity of remyelination at the level of the spinal cord, although some differences can be detected at the level of the brain between the two groups [96].

\section{Conventional Imaging}

Spinal cord imaging is performed less frequently than brain imaging in patients with MS. Several factors can affect the imaging quality, resulting in artifacts, such as the small dimensions of the spinal cord, the surrounding structures (i.e. bone, fat and cerebrospinal fluid [CSF]), which create magnetic field inhomogeneities, and physiological movements (CSF pulsation, cardiac and respiratory rhythmic motions), Still, spinal cord imaging is crucial to the diagnosis and prognosis of the disease, and guidelines for a recommended MR spinal cord protocol have been published $[97,98]$.

In patients with MS, the cervical tract of the spinal cord has a greater lesion load than do other tracts [99], and it is the most commonly studied tract. In the first study quantifying the cervical spinal cord lesion load in different clinical subtypes, the authors found a significantly higher lesion load in both SP-MS and PPMS patients than in RR-MS patients, with the higher load associated with clinical disability [100].

A spinal cord syndrome is the most common onset in patients with PP-MS [101] and, in the most recent revised 2017 McDonald criteria, the presence of lesions in the spinal cord is confirmed among the MR criteria for dissemination in space and for the diagnosis of PP-MS [1]. Moreover, the number of spinal cord lesions has been found to predict conversion from radiologically isolated syndrome (RIS) to PP-MS [102].

\section{Advanced MRI Techniques}

\section{Magnetization Transfer Ratio}

Magnetization transfer ratio abnormalities in the pial and subpial regions of the spinal cord are more marked in patients with PMS compared to the early stages, hinting at subpial demyelination as the underlying pathological process, possibly related to meningeal inflammation [103]. In a MTR study of PP-MS and SPMS patients, the two groups showed a comparable diffuse damage of the cervical spinal cord, although the latter group presented the greater lesion burden [26].

\section{Diffusion Tensor Imaging}

Although advanced techniques and analytical models for the application of DTI metrics to the spinal cord represent an active research field, a unified method of analysis has not been defined to date, and the potential use of DTI metrics in clinical trials is still far from practical implementation [104].

Similar to what has been found for the volumetric measures, no relationship between DTI metrics of the brain and those of the spinal cord has been found in PP-MS patients. However, in one study reduced FA and higher MD content at the level of the cervical spinal cord were found in the patient group relative to healthy controls [105].

MD and RD at the level of the posterior columns have been found to be significantly higher in SP-MS patients than in patients with RR-MS. Moreover, FA, MD and RD of the spinal cord GM have also been found more altered in SP-MS patients than in those with RR-MS or clinically isolated syndrome (CIS), and GM RD is also correlated with clinical disability [103].

In a longitudinal diffusion MR study on RRMS, SP-MS and PP-MS patients, over a mean follow-up of 2.4 years, the decrease in FA of the cervical segment was reported to be higher in patients with PP-MS. However, the worsening in DTI metrics did not correlate with supratentorial damage or with the extent of the local lesion load [106].

\section{T1-Derived Measures of Atrophy}

Several different methods are currently available to evaluate cervical spinal cord atrophy in patients with MS, including the measurement of the cross-sectional area at several anatomical levels or measurment of the volume between two levels (Fig. 2) [107, 108].

Diffuse axonal degeneration is more responsible than local inflammatory lesions for spinal 


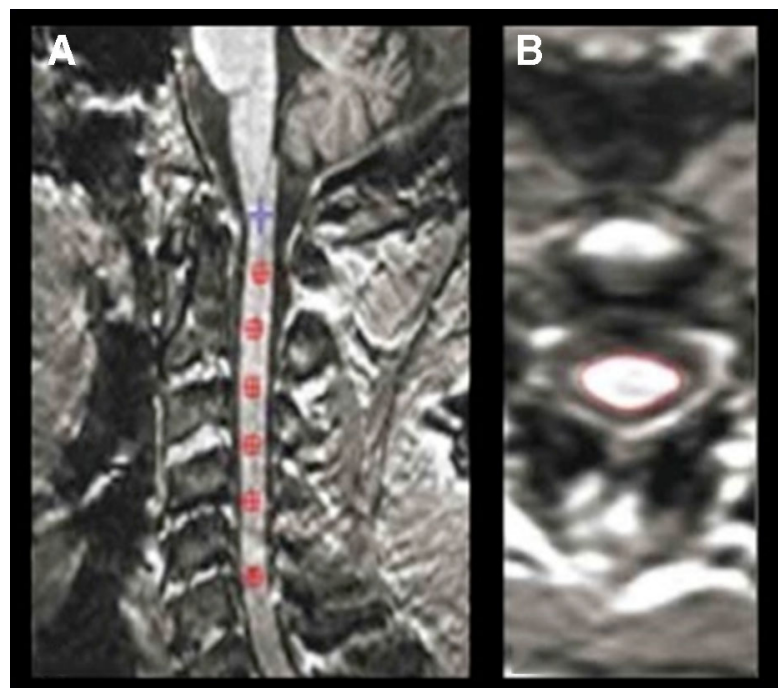

Fig. 2 Example of spinal cord volume measurement on a three-dimensional (3D) T1-weighted image from a patient with progressive multiple sclerosis (PMS) (Jim, ver. 6). a Using the inferior border of C5 as a reference, a marker was placed at this level and then, moving back from C5, a marker was set every 10 slices until the first marker at C2 was reached (b), with the final output with the outlined cord shown

cord atrophy [109]. Spinal cord atrophy is present from the early stages of MS onwards, is faster in patients with disease progression [110] and is predictive of disability. In two studies, patients with PMS presented a higher lesion load and atrophy at both the cervical and thoracic levels than did patients with RR-MS [100, 111]; additionally, the spinal cord area at both levels, in particular that of the GM, was found to correlate with clinical disability [111]. Although the area of the upper cervical segments is the preferred area of study, Zeydan and colleagues observed that the $\mathrm{C} 7$ area presented the greatest difference between patients with RR-MS and those with SPMS at the early disease stages [112]. In their study involving 26 PP-MS patients, Ruggieri et al. found a smaller cervical spinal cord volume (at both the C2-C3 and C2-C5 levels) in their patients compared to the healthy controls, but spinal cord atrophy did not correlate with brain lesion load or volume [16].

In a longitudinal study of PP-MS patients with a radiological follow-up of 15 months, Rocca and colleagues acquired brain and spinal cord tissue and detected a significant decrease in cervical cord cross-sectional area [113]. In a cohort of 56 SP-MS patients, Furby and colleagues found that the spinal cord cross-sectional area presented the highest annual rate of atrophy among other MRI measures and correlated with changes in the Multiple Sclerosis Functional Composite (MSFC) measure [114]. Finally, Cawley et al. studied a population of PMS, and at the 1-year follow-up they found that the spinal cord cross-sectional area was significantly reduced in PP-MS patients, but not in SP-MS patients, when compared to healthy controls. Moreover, they calculated that the sample size for a 12-month neuroprotective clinical trials in PP-MS patients which would be required to observe a treatment effect of $50 \%$ would have been 57 subjects per arm, leading the authors to conclude that spinal cord atrophy could be used as an outcome measure in clinical trials [115]. In this study, the authors used the active surface model method to assess changes in cross-sectional area, a method which has been proved to be reliable and have good reproducibility [103].

Indeed, the role of spinal cord atrophy as an outcome measure has been assessed in a few clinical trials of patients with PMS. In a phase II study assessing the safety and efficacy of IFN beta-1b versus placebo in 70 patients with PPMS, Montalban et al. found no differences in the cervical spinal cord area between the two arms [116]. In another exploratory trial in PPMS patients, this time testing the efficacy of IFN beta-1a versus placebo, Leary et al. [117] again found no differences in the spinal cord measures (number of lesions and atrophy) between the two groups. Finally, no differences in cervical spinal cord area were found in a trial testing the neuroprotective effects of lamotrigine versus placebo in SP-MS patients [88].

It is possible to introduce spinal cord damage as an end-point measure in clinical trials in patients with PMS, in particular in the PP-MS group. However, a standardized approach with specific MR protocols, including high-resolution images for a precise detection of lesion load and the choice of a reproducible and a reliable method to calculate atrophy in longitudinal evaluation, are recommended. 


\section{CEREBELLUM}

\section{Pathological Features}

The cerebellum is a predilection site for demyelination in patients with MS [118], with the cerebellar cortex in particular having been shown to be more demyelinated than the cortical regions of the forebrain. This cortical demyelination occurs even in absence of WM damage.

A post-mortem study of PMS patients found a higher rate of cortical demyelination at the level of the cerebellum and spinal cord [90]. The pathology of Purkinje cells, which are responsible for the output signal from the cerebellum, have also been described within areas of cortical demyelination [119]. Meningeal inflammation has been detected in SP-MS patients at the level of the cerebellum and in association with cortical demyelination and found to be independent of the presence of follicle-like structures [120].

\section{Advanced MRI Techniques}

\section{Diffusion Tensor Imaging}

Reduced FA and increased RD values at the level of the middle cerebellar peduncle have been reported in patients with PP-MS in comparison to both the healthy controls and RR-MS patients; the abnormality of the DT metrics was clinically eloquent in terms of disability of the upper and lower limbs [121].

\section{T1-Derived Measures of Atrophy}

Cerebellar cortical volume loss has been detected in MS patients at all stages of the disease, from the very early stage onwards [122].

Although several technical difficulties hamper the reliability of cerebellar volume measurement, a number of automated and semiautomated image analysis methods have been developed and implemented in recent years (Fig. 3). In one study, cerebellar GM volume was found to be reduced in SP-MS patients compared to healthy controls [123]. In another study, atrophy of specific cerebellar lobules in PMS patients correlated with clinical disability, as assessed by means of 9-hole-peg-test and cognitive tests [124].

Longitudinal observations in PP-MS patients demonstrated a higher rate of atrophy in the cerebellar cortex over 5 years in comparison with healthy controls [125]; there was also a greater volume loss in patients, showing disease progression [126]. These observations suggest a potential role for cerebellar volume as an imaging outcome in clinical trials. In this study, the sample size necessary to consider cerebellar volume as a possible outcome was found to be

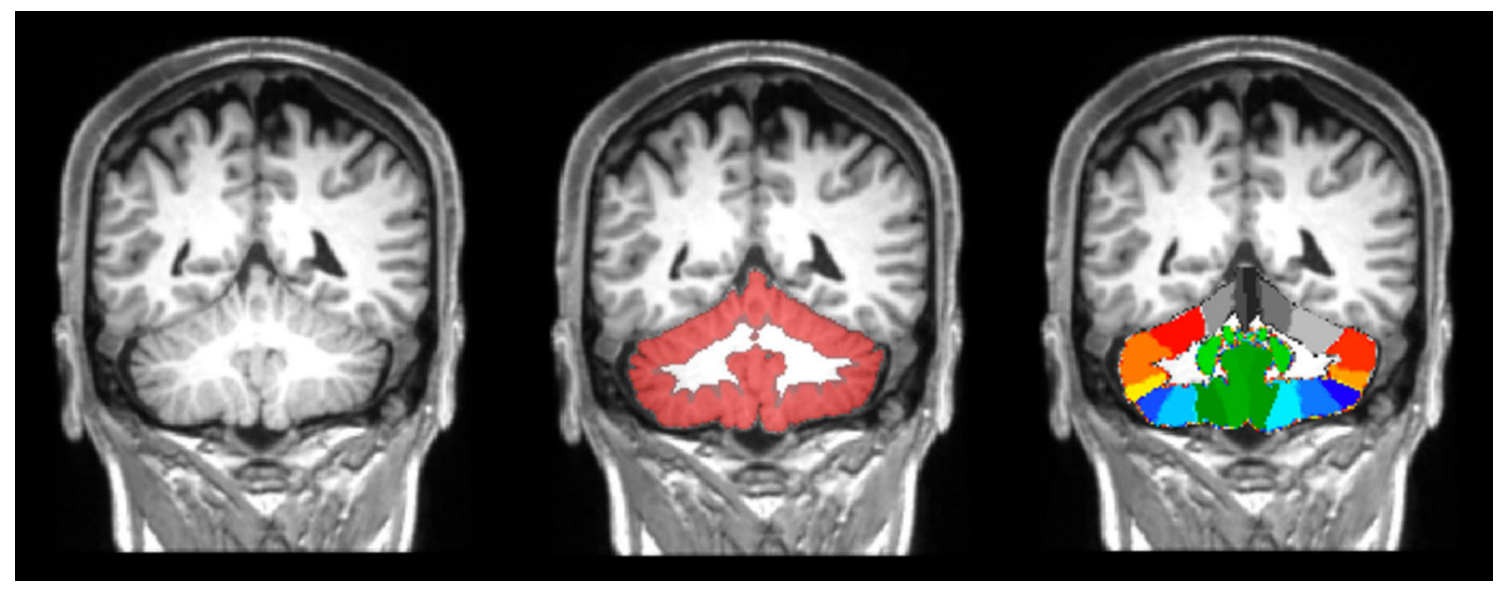

Fig. 3 Example of cerebellar segmentation on a 3D T1-weighted image from a patient with PMS. Middle image: the isolated cerebellar grey matter obtained by SUIT (spatially unbiased infratentorial toolbox), shown in red, is superimposed to the T1-weighted image. Right image: the SUIT cerebellar atlas aligned in the native subject space. Reproduced from Cocozza et al. [124] 
relatively small and thus easily applicable in clinical trials.

\section{DEEP GREY MATTER}

\section{Pathological Features}

The pathology of DGM in MS is characterized by the presence of focal lesions and atrophy and by increased iron content in both RR-MS and PMS patients. Demyelination of DGM nuclei is also a pathological hallmark of the disease. Demyelinating lesions are more often observed at the level of the thalamus and caudate; they involve both GM and WM and show an immunopathological pattern similar to the WM lesions but with lower degree of inflammation and axonal damage $[127,128]$.

\section{Advanced MRI Techniques}

\section{Susceptibility Weighted Imaging}

Reports of iron content in the DGM and in particular in the DGM nuclei of PMS patients are conflicting. Using $\mathrm{R}_{2}{ }^{*}$ mapping, Ropele et al. reported increased DGM iron levels in a group of RR-MS, SP-MS and PP-MS patients compared to healthy controls, although the thalamus was not included as a region of interest, and the result was primarily driven by the RR-MS group [129]. In PP-MS patients, iron content in the putamen has been found to be positively associated with the Expanded Disability Status Scale (EDSS) score [130]. A comparison of iron concentration across phenotypes revealed a progressive accumulation of iron in the DGM through the different MS stages [131].

However, a recent study using quantitative susceptibility maps has reported reduced iron content in the thalamus of RR-MS and SP-MS patients, with this reduction being significantly associated with disease duration [132]. The authors of this study advanced the hypothesis that iron loss associated with disease progression could be explained by the loss of oligodendrocytes, since these cells and their processes contain most of the iron in the WM and DGM in the brain [132].

\section{T1-Derived Measures of Atrophy}

In patients with PP-MS, atrophy of the thalami is detected in the first years of the disease $[125,133]$, and the thalamic volume has been found to be correlated with global and frontal lobe cortical lesion load [16]. These findings are supported by a study combining histopathological and MR techniques that found an association between thalamic cell density and volume loss of the corresponding cortical areas [134].

Very few studies have evaluated longitudinal changes in DGM volume in PMS patients. Several drawbacks are encountered when dealing with both global and local volume measurements. Specifically, in studies on DGM, the availability of different software for analysing segmentation and the choice of different statistical methods have resulted in inconsistent results across different studies. Similar to crosssectional studies, in longitudinal studies sequence parameters, image resolution, quality and head positioning can affect the output [135]. Mesaros et al. described increased thalamic atrophy in patients with PP-MS compared to healthy controls at a follow-up of 15 months. In a study of different MS clinical subtypes (CIS, RR-MS and SP-MS), with an average follow-up of 4.1 years, Azevedo et al. reported that thalamic volume loss was higher in patients than in healthy controls but that this volume loss was consistent across the different MS subtypes [136]. Conversely, the study of Eshaghi et al., with a larger patient sample that included all MS phenotypes and an average follow-up of 2.4 years, found that the DGM atrophy rate was higher in patients with PMS (both SP-MS and PP-MS) than in those with CIS and healthy controls [85]. Moreover, thalamus volume at baseline was predictive of disability progression at follow-up. In a 24-month study including patients with CIS, RR-MS and SP-MS, the sample size needed to detect significant changes was to be $80-100$ subjects per arm, thus supporting the measure of thalamic volume as an MRI endpoint in clinical trials of neuroprotective agents [136]. 
Table 1 Application of imaging techniques for the monitoring of disease progression

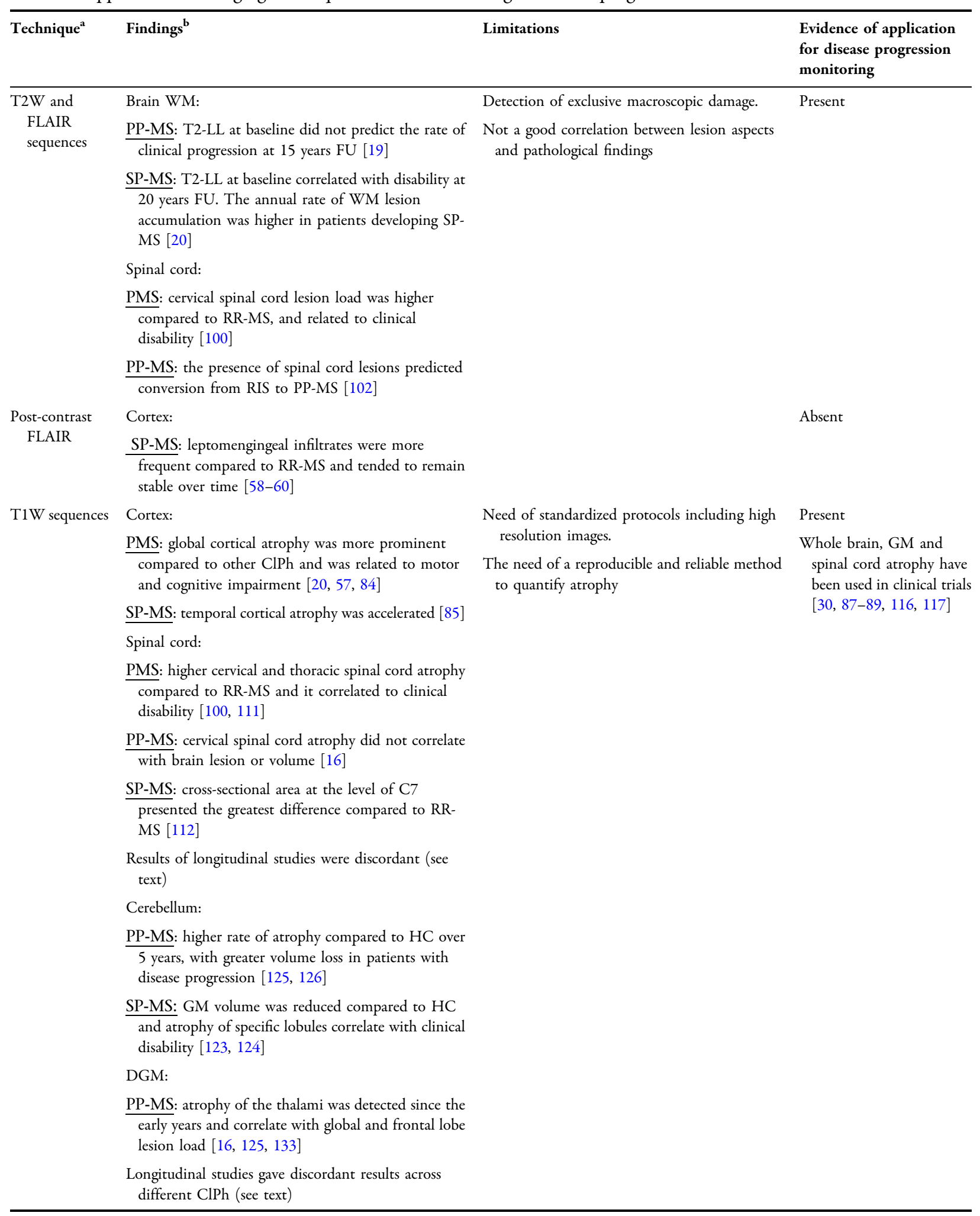


Table 1 continued

\begin{tabular}{|c|c|c|c|}
\hline Technique $^{\mathrm{a}}$ & Findings $^{b}$ & Limitations & $\begin{array}{l}\text { Evidence of application } \\
\text { for disease progression } \\
\text { monitoring }\end{array}$ \\
\hline MT imaging & $\begin{array}{l}\text { Brain WM: } \\
\text { PMS: NAWM damage assessed by MTR was higher } \\
\text { compared to other CIPh but did not differ between } \\
\text { SP and PP-MS }[24,25] \\
\text { PP-MS: MTR values of NAWM were lower } \\
\text { compared to HC. MTR values of the lesions were } \\
\text { decreased compared to NAWM. Lower NAWM } \\
\text { MTR values at baseline predicted a more severe } \\
\text { disability progression [22, 23, 27, 28] } \\
\text { Cortex: } \\
\text { PMS: demyelination at the level of the normal } \\
\text { appearing GM, assessed by MTR, correlated with } \\
\text { clinical disability and was sensitive to treatment } \\
\text { effects [27, 31, 33, 70] } \\
\text { Spinal cord: } \\
\text { PMS: damage assessed by MTR was more pronounced } \\
\text { in the pial and subpial regions compared to other } \\
\text { ClPh. Damage was comparable between PP- and SP- } \\
\text { MS patients [26, 103] }\end{array}$ & $\begin{array}{l}\text { MTR could be influenced by several factors } \\
\text { (axonal loss, inflammation, edema) } \\
\text { MTR responsiveness to changes seems to be } \\
\text { limited }\end{array}$ & $\begin{array}{l}\text { Present } \\
\text { MTR has been used in } \\
\text { clinical trials }[29-31]\end{array}$ \\
\hline DTI & $\begin{array}{l}\text { Brain WM: } \\
\text { PMS: NAWM damage, assessed by diffusion imaging, } \\
\text { was less affected in PP-MS compared to SP-MS } \\
\text { [38, 42] } \\
\text { PP-MS: DTI metrics were altered compared to HC. } \\
\text { No overlap between diffusivity and T2 lesion maps } \\
\text { suggests axonal damage and focal lesions are } \\
\text { independent processes [38, 41] } \\
\text { SP-MS: diffusion abnormalities were more } \\
\text { pronounced compared to RR-MS [38, 40] } \\
\text { Cortex: } \\
\text { PMS: changes in DTI metrics were more severe } \\
\text { compared to RR-MS. DTI parameters could detect } \\
\text { increased damage over } 1 \text { year, not correlated with T2 } \\
\text { lesion load and brain atrophy [ } 42,71,72] \\
\text { Spinal cord: } \\
\text { PMS: among PP, SP and RR patients the former had } \\
\text { the most marked decrease of FA values in the } \\
\text { cervical segment over a mean of } 2.4 \text { years FU [106] } \\
\text { PP-MS: DTI metrics were altered compared to HC } \\
\text { [105] } \\
\text { SP-MS: DTI metrics were altered both at the level of } \\
\text { the posterior columns and GM of the spinal cord } \\
\text { compared to RR-MS patients. GM RD correlated } \\
\text { with disability [103] } \\
\text { Cerebellum: } \\
\text { PP-MS: altered DTI metrics at the level of the middle } \\
\text { cerebellar peduncle compared to HC and RR-MS. } \\
\text { They correlated with clinical disability [121] }\end{array}$ & $\begin{array}{l}\text { Lack of pathological specificity } \\
\text { Need of variable sample size depending on the } \\
\text { specific metric and area of the brain. } \\
\text { The need to use advanced models to better } \\
\text { describe the complexity of brain tissue and to } \\
\text { characterize different pathological processes }\end{array}$ & $\begin{array}{l}\text { Present } \\
\text { Diffusion based MRI } \\
\text { parameters have been } \\
\text { used in clinical trials } \\
{[30,31,43]}\end{array}$ \\
\hline
\end{tabular}


Table 1 continued

\begin{tabular}{|c|c|c|c|}
\hline Technique $^{a}$ & Findings ${ }^{b}$ & Limitations & $\begin{array}{l}\text { Evidence of application } \\
\text { for disease progression } \\
\text { monitoring }\end{array}$ \\
\hline $\begin{array}{l}\text { MR } \\
\text { spectroscopy }\end{array}$ & $\begin{array}{l}\text { Brain WM: } \\
\text { PP-MS: NAA of NAWM was found lower compared } \\
\text { to HC but not when compared to other ClPh } \\
{[47,48]} \\
\text { Cortex: } \\
\text { PMS: A NAA decrease has been found in the cortical } \\
\text { GM }[41,82] \text {. } \\
\text { Longitudinal studies gave negative results }[49,83]\end{array}$ & & $\begin{array}{l}\text { Absent } \\
\text { MR spectroscopy has been } \\
\text { used in clinical trials [ } 49]\end{array}$ \\
\hline $\begin{array}{c}\text { PET with } \\
\text { TSPO }\end{array}$ & $\begin{array}{l}\text { Brain WM: } \\
\frac{\text { PMS: increased uptake in NAWM, related to clinical }}{\text { severity and patient age [52] }} \\
\frac{\text { SP-MS: the uptake was increased in NAWM }}{\text { compared to HC suggesting persisting inflammation }} \\
\text { [53] } \\
\text { Cortex: } \\
\frac{\text { PMS: persistent cortical inflammation at the level of }}{\text { the cortex and cortical lesions, related to clinical }} \\
\text { disability [52] }\end{array}$ & Invasive and expensive tool & Absent \\
\hline SWI/T2* & $\begin{array}{l}\text { Cortex: } \\
\text { PMS: a gradient of cortical pathology has been } \\
\text { showed, with superficial layers involved early } \\
\text { compared to deeper ones [81] } \\
\text { DGM: } \\
\frac{\text { PMS: studies on the iron content at the level of DGM }}{\text { gave discordant results (see text) }}\end{array}$ & & Absent \\
\hline
\end{tabular}

$\overline{{ }^{a}}$ TIW/T2W T1/T2-weighted, FLAIR fluid-attenuated inversion recovery, $M T$ magnetization transfer, DTI diffusion tensor imaging, MR magnetic resonance, $P E T$ positron-emission tomography, TSPO translocator protein, $S W I$ susceptibility-weighted imaging

${ }^{b} W M$ White matter, $P P-M S$ primary progressive multiple sclerosis, $R I S$ radiologically isolated syndrome $S P-M S$ secondary progressive multiple sclerosis, $R R$ - $M S$ relapsing-remitting multiple sclerosis, $P M S$ progressive multiple sclerosis, $T 2-L L$ T2-lesion load, $F U$ follow-up, $D G M$ deep grey matter, $N A W M$ normal-appearing white matter, $H C$ healthy controls, $G M$ grey matter, $M T R$ magnetization transfer ratio, $N A A N$-acetyl-aspartate, $C l P h$ clinical phenotypes, $R D$ radial diffusivity, $F A$ fractional anisotropy

\section{RECENT ADVANCEMENTS AND FUTURE PERSPECTIVES}

One of the barriers to assessing potential neuroprotective agents in MS is the slow rate of disability accrual. Thus, clinical disability outcome measures exhibit a poor sensitivity when applied to small groups of patients over relatively short periods of time. MRI surrogates are more sensitive to disease activity, and current MRI measures of tissue inflammation, such as gadolinium-enhancing and new T2 lesion count, are useful to monitor response to antinflammatory agents in patients with RR-MS. MRI measures of inflammation, however, are insensitive markers in patients with PMS since the underlying pathology is dominated by diffuse damage to brain GM and WM and a worsening of tissue damage within existing lesions rather than by the accumulation of new brain WM lesions. Nonetheless, a role for MRI measures of active inflammation has been recently acknowledged in PMS patients with an ongoing inflammatory process [137], highlighting the importance of selecting pertinent outcomes in relation to the characteristics of the investigated population when designing clinical trial (Table 1). 


\section{CONCLUSION}

The ideal neuroimaging biomarker for PMS monitoring should offer high specificity for the pathophysiological mechanisms underlying tissue damage, be sensitive to change over a short time period and be reproducible across multiple sites, with the aim to facilitate standardization and application in multicentre clinical trials. Although much progress has been made in terms of developing more specific MRI markers, only a few longitudinal studies have explored the sensitivity of these markers over time due to the technical challenges related to standardization of advanced imaging protocols and post-processing techniques. Among the available markers, brain atrophy seems the closest option to bridge the gap between research and clinical application, with DGM volume and the cerebellum showing a high sensitivity among the regional metrics [85, 126], while other advanced techniques characterizing tissue microstructure should be selected for exploratory trials to answer specific questions about drug efficacy in neuroprotection and tissue repair. In particular, MTR-based imaging or multi-compartment diffusion imaging might be useful to investigate the effect of drugs promoting remyelination, while post-contrast FLAIR could be applied to investigate the monitoring response to drugs targeting $B$ cells.

\section{ACKNOWLEDGEMENTS}

Funding. No funding or sponsorship was received for this study or publication of this article.

Authorship. All named authors meet the International Committee of Medical Journal Editors (ICMJE) criteria for authorship for this article, take responsibility for the integrity of the work as a whole, and have given their approval for this version to be published.

Disclosures. Maria Petracca, Monica Margoni and Giulia Bommarito declare that they have nothing to disclose. Matilde Inglese has received research grants from Novartis Pharmaceuticals, the National Multiple Sclerosis Society, the Noto Foundation, NIH and TEVA Neuroscience.

Compliance with Ethics Guidelines. This article is based on previously conducted studies and does not contain any studies with human participants or animals performed by any of the authors.

Open Access. This article is distributed under the terms of the Creative Commons Attribution-NonCommercial 4.0 International License (http://creativecommons.org/licenses/ by-nc/4.0/), which permits any noncommercial use, distribution, and reproduction in any medium, provided you give appropriate credit to the original author(s) and the source, provide a link to the Creative Commons license, and indicate if changes were made.

\section{REFERENCES}

1. Thompson AJ, Banwell BL, Barkhof F, et al. Diagnosis of multiple sclerosis: 2017 revisions of the McDonald criteria. Lancet Neurol. 2018;17(2):162-73.

2. Lublin FD, Reingold SC, Cohen JA, et al. Defining the clinical course of multiple sclerosis: the 2013 revisions. Neurology. 2014;84(9):963.

3. Choi SR, Howell OW, Carassiti D, et al. Meningeal inflammation plays a role in the pathology of primary progressive multiple sclerosis. Brain. 2012;135(10):2925-37.

4. Hutchinson M. Neurodegeneration in multiple sclerosis is a process separate from inflammation: no. Mult Scler. 2015;21(13):1628-31.

5. Louapre C, Lubetzki C. Neurodegeneration in multiple sclerosis is a process separate from inflammation: yes. Mult Scler J. 2015;21(13):1626-8.

6. Lassmann H. Targets of therapy in progressive MS. Mult Scler. 2017;23(12):1593-9.

7. Tur C, Moccia M, Barkhof F, , et al. Assessing treatment outcomes in multiple sclerosis trials and in the clinical setting. Nat Rev Neurol. 2018;14(2):75-93. 
8. Frischer JM, Weigand SD, Guo Y, et al. Clinical and pathological insights into the dynamic nature of the white matter multiple sclerosis plaque. Ann Neurol. 2015;78(5):710-21.

9. Dal-Bianco A, Grabner G, Kronnerwetter C, et al. Slow expansion of multiple sclerosis iron rim lesions: pathology and $7 \mathrm{~T}$ magnetic resonance imaging. Acta Neuropathol. 2017;133(1):25-42.

10. Kutzelnigg A, Lucchinetti CF, Stadelmann C, et al. Cortical demyelination and diffuse white matter injury in multiple sclerosis. Brain. 2005;128(11): 2705-12.

11. Hochmeister S, Grundtner R, Bauer J, et al. Dysferlin is a new marker for leaky brain blood vessels in multiple sclerosis. J Neuropathol Exp Neurol. 2006;65(9):855-65.

12. Miller DH, Grossman RI, Reingold SC, McFarland HF. The role of magnetic resonance techniques in understanding and managing multiple sclerosis. Brain. 1998;121(1):3-24.

13. Barkhof F, Brück W, De Groot CJ, et al. Remyelinated lesions in multiple sclerosis. Arch Neurol. 2003;60(8):1073-81.

14. Bitsch A, Kuhlmann T, Stadelmann C, Lassmann H, Lucchinetti C, Bru W. A longitudinal MRI study of histopathologically defined hypointense multiple sclerosis lesions. Ann Neurol. 2001;49(6):793-816.

15. Miller DH, Leary SM. Primary-progressive multiple sclerosis. Lancet Neurol. 2007;6(10):903-12.

16. Ruggieri S, Petracca M, Miller A, et al. Association of deep gray matter damage with cortical and spinal cord degeneration in primary progressive multiple sclerosis. JAMA Neurol. 2015;72(12):1466-74.

17. Ingle GT, Sastre-Garriga J, Miller DH, Thompson AJ. Is inflammation important in early PPMS? A longitudinal MRI study. J Neurol Neurosurg Psychiatry. 2005;76(9):1255-8.

18. Khaleeli Z, Ciccarelli O, Mizskiel K, Altmann D, Miller DH, Thompson AJ. Lesion enhancement diminishes with time in primary progressive multiple sclerosis. Mult Scler. 2010;16(3):317-24.

19. Mostert JP, Koch MW, Steen C, Heersema DJ, De Groot JC, De Keyser J. T2 lesions and rate of progression of disability in multiple sclerosis. Eur J Neurol. 2010;17:1471-5.

20. Fisniku LK, Brex PA, Altmann DR, et al. Disability and T2 MRI lesions: a 20-year follow-up of patients with relapse onset of multiple sclerosis. Brain. 2008;131(3):808-17.
21. Van Waesberghe JHTM, Kamphorst W, De Groot CJA, et al. Axonal loss in multiple sclerosis lesions: magnetic resonance imaging insights into substrates of disability. Ann Neurol. 1999;46(5):747-54.

22. Gass A, Barker GJKD, Kidd D, et al. Correlation of magnetization transfer ratio with clinical disability in multiple sclerosis. Ann Neurol. 1994;36(1):62-7.

23. Leary SM, Silver NC, Stevenson VL, Barker GJ, Miller $\mathrm{DH}$, Thompson AJ. Magnetisation transfer of normal appearing white matter in primary progressive multiple sclerosis. Mult Scler J. 1999;5(5):313-6.

24. Filippi M, Iannucci G, Tortorella C, et al. Comparison of MS clinical phenotypes using conventional and magnetization transfer MRI. Neurology. 1999;52(3):588.

25. Tortorella C, Viti B, Bozzali M, et al. A magnetization transfer histogram study of normal-appearing brain tissue in MS. Neurology. 2000;54(1):186.

26. Rovaris M, Bozzali M, Santuccio G, et al. In vivo assessment of the brain and cervical cord pathology of patients with primary progressive multiple sclerosis. Brain. 2001;124(12):2540-9.

27. Khaleeli Z, Sastre-Garriga J, Ciccarelli O, Miller DH, Thompson AJ. Magnetisation transfer ratio in the normal appearing white matter predicts progression of disability over 1 year in early primary progressive multiple sclerosis. J Neurol Neurosurg Psychiatry. 2007;78(10):1076-82.

28. Khaleeli Z, Ciccatelli O, Manfredonia F, et al. Predicting progression in primary progressive multiple sclerosis: a 10-year multicenter study. Ann Neurol. 2008;63(6):790-3.

29. Connick P, Kolappan M, Crawley C, et al. Autologous mesenchymal stem cells for the treatment of secondary progressive multiple sclerosis: an openlabel phase 2 a proof-of-concept study. Lancet Neurol. 2012;11(2):150-6.

30. Fox RJ, Coffey CS, Cudkowicz ME, et al. Design, rationale, and baseline characteristics of the randomized double-blind phase II clinical trial of ibudilast in progressive multiple sclerosis. Contemp Clin Trials. 2016;50:166-77.

31. Christensen JR, Ratzer R, Börnsen L, et al. Natalizumab in progressive MS: results of an open-label, phase 2A, proof-of-concept trial. Neurology. 2014;82(17):1499-507.

32. Inglese M, van Waesberghe JHTM, Rovaris M, et al. The effect of interferon-1b on quantities derived from MT MRI in secondary progressive MS. Neurology. 2003;60(5):853-60. 
33. Hayton T, Furby J, Smith KJ, et al. Longitudinal changes in magnetisation transfer ratio in secondary progressive multiple sclerosis: data from a randomised placebo controlled trial of lamotrigine. J Neurol. 2012;259(3):505-14.

34. Filippi M, Inglese $M$, Rovaris $M$, et al. Magnetization transfer imaging to monitor the evolution of MS: a 1-year follow-up study [In Process Citation]. Neurology. 2000;55(7):940-6.

35. Rovaris M, Filippi M, Calori G, et al. Intra-observer reproducibility in measuring new putative MR markers of demyelination and axonal loss in multiple sclerosis: a comparison with conventional T2weighted images. J Neurol. 1997;244(4):266-70.

36. Inglese M, Bester M. Diffusion imaging in multiple sclerosis: research and clinical implications. NMR Biomed. 2010;23:865-72.

37. Filippi M, Iannucci GMC. A quantitative study of water diffusion in multiple sclerosis lesions and normal-appearing white matter using echo-planar imaging. Arch Neurol. 2000;57:1017-21.

38. Preziosa P, Rocca MA, Caputo D. Intrinsic damage to the major white matter tracts in patients with different clinical phenotypes of multiple sclerosis: a voxelwise diffusion tensor MR study. Radiology. 2011;260(2):541-50.

39. Ceccarelli A, Rocca MA, Valsasina P, et al. A multiparametric evaluation of regional brain damage in patients with primary progressive multiple sclerosis. Hum Brain Mapp. 2009;30(9):3009-19.

40. Scanderbeg AC, Tomaiuolo F, Sabatini U, Nocentini U, Grasso MG, Caltagirone C. Demyelinating plaques in relapsing-remitting and secondary-progressive multiple sclerosis: assessment with diffusion MR imaging. Am J Neuroradiol. 2000;21(5):862-8.

41. Sijens PE, Mostert JP, Oudkerk M, De Keyser J. 1H MR spectroscopy of the brain in multiple sclerosis subtypes with analysis of the metabolite concentrations in gray and white matter: initial findings. Eur Radiol. 2006;16(2):489-95.

42. Marco Rovaris, Bozzali Marco GI. Assessment of normal-appearing white and gray matter in patients with primary progressive multiple sclerosis. Arch Neurol. 2002;59:1406-12.

43. Cambron M, Haentjens $\mathrm{P}, \mathrm{D}^{\prime}$ Hooghe $\mathrm{M}$, et al. Fluoxetine in progressive multiple sclerosis (FLUOXPMS): study protocol for a randomized controlled trial. Trials. 2014;15(1):1-7.

44. Harrison DM, Caffo B, Shiee N, et al. Longitudinal changes in diffusion tensor-based quantitative
MRI in multiple sclerosis. Neurology. 2011;76: 179-86.

45. Tkáč I. Methodology of MRS in animal models: technical challenges and solutions. In: Öz G, ed Magnetic Resonance Spectroscopy of Degenerative Brain Diseases (series Contemporary Clinical Neuroscience). Basel: Springer International Publishing; 2016:13-30.

46. Inglese M, Rusinek H, George IC, Babb JS, Grossman RI, Gonen O. Global average gray and white matter $\mathrm{N}$-acetylaspartate concentration in the human brain. Neuroimage. 2008;41(2):270-6.

47. Suhy J, Rooney WD, Goodkin DE, et al. 1H MRSI comparison of white matter and lesions in primary progressive and relapsing-remitting MS. Mult Scler. 2000;6(3):148-55.

48. Vrenken H, Barkhof F, Uitdehaag BMJ, Castelijns JA, Polman $\mathrm{CH}$, Pouwels PJW. MR spectroscopic evidence for glial increase but not for neuro-axonal damage in MS normal-appearing white matter. Magn Reson Med. 2005;53(2):256-66.

49. Sajja B, Narayana P, Wolinsky J. Longitudinal magnetic resonance spectroscopic imaging of primary progressive multiple sclerosis patients treated with glatiramer acetate: multicenter study. Mult Scler. 2008;14:73-80.

50. Banati RB, Newcombe J, Gunn RN, et al. The peripheral benzodiazepine binding site in the brain in multiple sclerosis. Quantitative in vivo imaging of microglia as a measure of disease activity. Brain. 2000;123:2321-37.

51. Cosenza-Nashat M, Zhao ML, Suh HS, et al. Expression of the translocator protein of $18 \mathrm{kDa}$ by microglia, macrophages and astrocytes based on immunohistochemical localization in abnormal human brain. Neuropathol Appl Neurobiol. 2009;35(3):306-28.

52. Herranz E, Giannì C, Louapre C, et al. Neuroinflammatory component of gray matter pathology in multiple sclerosis. Ann Neurol. 2016;80(5):776-90.

53. Airas L, Nylund M, Rissanen E. Evaluation of microglial activation in multiple sclerosis patients using positron emission tomography. Front Neurol. 2018;9:181.

54. Lassmann H, Van Horssen J, Mahad D. Progressive multiple sclerosis: pathology and pathogenesis. Nat Rev Neurol. 2012;8:647-56.

55. Jürgens T, Jafari $M$, Kreutzfeldt $M$, et al. Reconstruction of single cortical projection neurons reveals primary spine loss in multiple sclerosis. Brain. 2016;139(1):39-46. 
56. Magliozzi R, Howell OW, Reeves C, et al. A Gradient of neuronal loss and meningeal inflammation in multiple sclerosis. Ann Neurol. 2010;68(4):477-93.

57. Pagani E, Rocca MA, Gallo A, et al. Regional brain atrophy evolves differently in patients with multiple sclerosis according to clinical phenotype. Am J Neuroradiol. 2005;26(2):341-6.

58. Absinta M, Vuolo L, Rao A, et al. Gadolinium-based MRI characterization of leptomeningeal inflammation in multiple sclerosis. Neurology. 2015;85(1): 18-28.

59. Makshakov G, Magonov E, Totolyan N, et al. Leptomeningeal contrast enhancement is associated with disability progression and grey matter atrophy in multiple sclerosis. Neurol Res Int. 2017;2017:8652463.

60. Haider L, Zrzavy T, Hametner S, et al. The topograpy of demyelination and neurodegeneration in the multiple sclerosis brain. Brain. 2016;139(3):807-15.

61. Absinta M, Cortese ICM, Vuolo L, et al. Leptomeningeal gadolinium enhancement across the spectrum of chronic neuroinflammatory diseases. Neurology. 2017;88(15):1439-44.

62. Sethi V, Muhlert N, Ron M, et al. MS cortical lesions on DIR: not quite what they seem? PLoS One. 2013;8(11):8-12.

63. Nielsen AS, Kinkel RP, Madigan N, Tinelli E, Benner T, Mainero C. Contribution of cortical lesion subtypes at 7T MRI to physical and cognitive performance in MS. Neurology. 2013;81(7):641-9.

64. Rinaldi F, Calabrese M, Seppi D, Puthenparampil M. Natalizumab strongly suppresses cortical pathology in relapsing-remitting multiple sclerosis. Mult Scler. 2012;18(12):1760-7.

65. Strijbis EMM, Kooi EJ, van der Valk P, Geurts JJG. Cortical remyelination is heterogeneous in multiple sclerosis. J Neuropathol Exp Neurol. 2017;76(5): 390-401.

66. Derakhshan M, Caramanos Z, Narayanan S, Arnold DL, Collins LD. Surface-based analysis reveals regions of reduced cortical magnetization transfer ratio in patients with multiple sclerosis: a proposed method for imaging subpial demyelination. Hum Brain Mapp. 2014;35(7):3402-13.

67. Peterson JW, Bö L, Mörk S, Chang A, Trapp BD. Transected neurites, apoptotic neurons, and reduced inflammation in cortical multiple sclerosis lesions. Ann Neurol. 2001;50(3):389-400.

68. Schmierer K, Scaravilli F, Altmann DR, Barker GJ, Miller DH. Magnetization transfer ratio and myelin in postmortem multiple sclerosis brain. Ann Neurol. 2004;56(3):407-15.

69. Davie CA, Silver NC, Barker GJ, et al. Does the extent of axonal loss and demyelination from chronic lesions in multiple sclerosis correlate with the clinical subgroup? J Neurol Neurosurg Psychiatry. 1999;67(6):710-5.

70. Hayton T, Furby J, Smith KJ, et al. Grey matter magnetization transfer ratio independently correlates with neurological deficit in secondary progressive multiple sclerosis. J Neurol. 2009;256(3): 427-35.

71. Bozzali M, Cercignani M, Sormani MP, Comi G, Filippi M. Quantification of brain gray matter damage in different MS phenotypes by use of diffusion tensor MR imaging. Am J Neuroradiol. 2002;23(6):985-8.

72. Rovaris M, Gass A, Bammer R, Hickman S. Diffusion MRI in multiple sclerosis. Neurology. 2005;25(4): 402-9.

73. Fox RJ, McColl RW, Lee J-C, Frohman T, Sakaie K, Frohman E. A preliminary validation study of diffusion tensor imaging as a measure of functional brain injury. Arch Neurol. 2008;65(9):1179-84.

74. Grech-Sollars M, Hales PW, Miyazaki K, et al. Multicentre reproducibility of diffusion MRI parameters for clinical sequences in the brain. NMR Biomed. 2015;28(4):468-85.

75. Winston GP. The potential role of novel diffusion imaging techniques in the understanding and treatment of epilepsy. Quant Imaging Med Surg. 2015;5(2):279-87.

76. Wei L, Wu B, Liu C. Quantitative susceptibility mapping of human brain reflects spatial variation in tissue composition. Neuroimage. 2011;55(4):164556.

77. Yao B, Bagnato F, Matsuura E. Chronic multiple sclerosis lesions: characterization with high-fieldstrength MR imaging. Radiology. 2012;262(1):2016-215.

78. Yao B, Hametner S, Van Gelderen P, et al. 7 Tesla magnetic resonance imaging to detect cortical pathology in multiple sclerosis. PLoS One. 2014;9(10):e108863.

79. Bagnato F, Hametner S, Yao B, et al. Tracking iron in multiple sclerosis: a combined imaging and histopathological study at 7 Tesla. Brain. 2011;134(12):3599-612.

80. Adad JC, Polimeni HKG Jr. T2* mapping and B0 orientation-dependence at $7 \mathrm{~T}$ reveal cyto- and 
myeloarchitecture organization of the human cortex. Neuroimage. 2012;60(2):1006-14.

81. Mainero C, Louapre C, Govindarajan ST, et al. A gradient in cortical pathology in multiple sclerosis by in vivo quantitative $7 \mathrm{~T}$ imaging. Brain. 2015;138(4):932-45.

82. Sastre-Garriga J, Ingle GT, Chard DT, et al. Metabolite changes in normal-appearing gray and white matter are linked with disability in early primary progressive multiple sclerosis. Arch Neurol. 2005;62(4):569-73.

83. Kirov II, Tal A, Babb JS, Herbert J, Gonen O. Serial proton MR spectroscopy of gray and white matter in relapsing-remitting MS. Neurology. 2013;80(1):39-46.

84. Fisher E, Lee JC, Nakamura K, Rudick RA. Gray matter atrophy in multiple sclerosis: a longitudinal study. Ann Neurol. 2008;64(3):255-65.

85. Eshaghi A, Prados F, Brownlee W, et al. Deep grey matter volume loss drives disability worsening in multiple sclerosis. Ann Neurol. 2018;L:1-13.

86. Altmann DR, Jasperse B, Barkhof F, et al. Sample sizes for brain atrophy outcomes in trials for secondary progressive multiple sclerosis. Neurology. 2009;72(7):595-601.

87. Chataway J, Schuerer N, Alsanousi A, et al. Effect of high-dose simvastatin on brain atrophy and disability in secondary progressive multiple sclerosis (MS-STAT): a randomised, placebo-controlled, phase 2 trial. Lancet. 2014;383(9936):2213-21.

88. Kapoor R, Furby J, Hayton T, et al. Lamotrigine for neuroprotection in secondary progressive multiple sclerosis: a randomised, double-blind, placebo-controlled, parallel-group trial. Lancet Neurol. 2010;9(7):681-8.

89. Barkhof F, Giovannoni G, Hartung H-P, et al. ARPEGGIO: a randomized, placebo-controlled study to evaluate oral laquinimod in patients with primary progressive multiple sclerosis (PPMS). Neurology. 2015;84[Suppl 14]:P7.210.

90. Gilmore CP, Bö L, Owens T, Lowe J, Esiri MM, Evangelou N. Spinal cord gray matter demyelination in multiple sclerosis-a novel pattern of residual plaque morphology. Brain Pathol. 2006;16(3):202-8.

91. Bergers E, Bot JCJ, van der Valk P, et al. Diffuse signal abnormalities in the spinal cord in multiple sclerosis: direct postmortem in situ magnetic resonance imaging correlated with in vitro high-resolution magnetic resonance imaging and histopathology. Ann Neurol. 2002;51(5):652-6.
92. Nijeholt GJ, Bergers E, Kamphorst W, et al. Postmortem high-resolution MRI of the spinal cord in multiple sclerosis: a correlative study with conventional MRI, histopathology and clinical phenotype. Brain. 2001;124(1):154-66.

93. Lovas G, Szilágyi N, Majtényi K, Palkovits M, Komoly S. Axonal changes in chronic demyelinated cervical spinal cord plaques. Brain. 2000;123(2): 308-17.

94. Bot JCJ, Blezer ELA, Kamphorst W, et al. The Spinal cord in multiple sclerosis: relationship of high-spatial-resolution quantitative $\mathrm{mr}$ imaging findings to histopathologic results. Radiology. 2004;233(2): 531-40.

95. Gilmore CP, Donaldson I, Bö L, Owens T, Lowe J, Evangelou N. Regional variations in the extent and pattern of grey matter demyelination in multiple sclerosis: a comparison between the cerebral cortex, cerebellar cortex, deep grey matter nuclei and the spinal cord. J Neurol Neurosurg Psychiatry. 2009;80(2):182-7.

96. Bramow S, Frischer JM, Lassmann $\mathrm{H}$, et al. Demyelination versus remyelination in progressive multiple sclerosis. Brain. 2010;133(10):2983-98.

97. Traboulsee A, Simon JH, Stone L, et al. Summary of MRI protocol and guidelines prepared by: revised recommendations of the CMSC task force for a standardized MRI protocol and clinical guidelines for the diagnosis and follow-up of multiple sclerosis. Am J Neuroradiol. 2016;37(3):394-401.

98. Rovira Á, Wattjes MP, Tintoré M, et al. Evidencebased guidelines: mAGNIMS consensus guidelines on the use of MRI in multiple sclerosis-clinical implementation in the diagnostic process. Nat Rev Neurol. 2015;11(8):471-82.

99. Oppenheimer DR. The cervical cord in multiple sclerosis. Neuropathol Appl Neurobiol. 1978;4(2): 151-62.

100. Kearney H, Altmann DR, Samson RS, et al. Cervical cord lesion load is associated with disability independently from atrophy in MS. Neurology. 2015;84(4):367-73.

101. Stevenson VL, Miller DH, Rovaris M, et al. Primary and transitional progressive MS: a clinical and MRI crosssectional study. Neurology. 1999;52(4):839-45.

102. Kantarci OH, Lebrun C, Siva A, et al. Primary progressive multiple sclerosis evolving from radiologically isolated syndrome. Ann Neurol. 2016;79(2):288-94.

103. Kearney H, Yiannakas MC, Samson RS, WheelerKingshott CAM, Ciccarelli O, Miller DH. 
Investigation of magnetization transfer ratioderived pial and subpial abnormalities in the multiple sclerosis spinal cord. Brain. 2014;137(9):2456-68.

104. Wheeler-Kingshott CA, Stroman PW, Schwab JM, et al. The current state-of-the-art of spinal cord imaging: applications. Neuroimage. 2014;84:1082-93.

105. Agosta F, Benedetti B, Rocca MA, Valsasina P, Rovaris M, Comi G. Quantification of cervical cord pathology in primary progressive MS using diffusion tensor MRI. Neurology. 2005;64:631-5.

106. Agosta F, Absinta M, Sormani MP, et al. In vivo assessment of cervical cord damage in MS patients: a longitudinal diffusion tensor MRI study. Brain. 2007;130(8):2211-9.

107. Oh J, Seigo MSE. Spinal cord normalization in multiple sclerosis. J Neuroimaging. 2014;24(6): 577-84.

108. Healy BC, Arora A, Hayden DL. Approaches to normalization of spinal cord volume: application to multiple sclerosis. J Neuroimaging. 2012;22(3): $1-16$.

109. Evangelou N, Deluca GC, Owens T, Esiri MM. Pathological study of spinal cord atrophy in multiple sclerosis suggests limited role of local lesions. Brain. 2005;128(1):29-34.

110. Lukas C, Knol DL, Sombekke MH, et al. Cervical spinal cord volume loss is related to clinical disability progression in multiple sclerosis. J Neurol Neurosurg Psychiatry. 2015;86(4):410-8.

111. Schlaeger R, Papinutto N, Zhu AH, et al. Association between thoracic spinal cord gray matter atrophy and disability in multiple sclerosis. JAMA Neurol. 2015;72(8):897-904.

112. Zeydan B, Gu X, Atkinson EJ, et al. Cervical spinal cord atrophy. Neurol Neuroimmunol Neuroinflammation. 2018;5(21):1-8.

113. Rocca MA, Sormani MP, Rovaris M, et al. Long-term disability progression in primary progressive multiple sclerosis: a 15-year study. Brain. 2017;140(11): 2814-9.

114. Furby J, Hayton T, Altmann D, et al. A longitudinal study of MRI-detected atrophy in secondary progressive multiple sclerosis. J Neurol. 2010;257(9): $1508-16$.

115. Cawley N, Tur C, Prados F, et al. Spinal cord atrophy as a primary outcome measure in phase II trials of progressive multiple sclerosis. Mult Scler. 2017. https://doi.org/10.1177/1352458517709954.
116. Montalban X, Sastre-Garriga J, Tintore M, et al. A single-center, randomized, double-blind, placebocontrolled study of interferon beta- $1 \mathrm{~b}$ on primary progressive and transitional multiple sclerosis. Mult Scler. 2009;15(10):1195-205.

117. Leary SM, Miller DH, Stevenson VL, Brex PA, Chard DT, Thompson AJ. Interferon beta-1a in primary progressive MS: an exploratory, randomized, controlled trial. Neurology. 2003;60(1):44-51.

118. Kutzelnigg A, Faber-Rod JC, Bauer J, et al. Widespread demyelination in the cerebellar cortex in multiple sclerosis. Brain Pathol. 2007;17(1):38-44.

119. Redondo J, Kemp K, Hares K, Rice C, Scolding N, Wilkins A. Purkinje cell pathology and loss in multiple sclerosis cerebellum. Brain Pathol. 2015;25(6):692-700.

120. Howell OW, Reeves CA, Nicholas R, et al. Meningeal inflammation is widespread and linked to cortical pathology in multiple sclerosis. Brain. 2011;134(9): 2755-71.

121. Anderson VM, Wheeler-Kingshott CAM, Abdel-Aziz $\mathrm{K}$, et al. A comprehensive assessment of cerebellar damage in multiple sclerosis using diffusion tractography and volumetric analysis. Mult Scler J. 2011;17(9):1079-87.

122. Calabrese M, Mattisi I, Rinaldi F, et al. Magnetic resonance evidence of cerebellar cortical pathology in multiple sclerosis magnetic resonance evidence of cerebellar cortical pathology in multiple sclerosis. J Neurol Neurosurg Psychiatry. 2010;81(4):401-4.

123. Anderson VM, Fisniku LK, Altmann DR, Thompson AJ, Miller DH. MRI measures show significant cerebellar gray matter volume loss in multiple sclerosis and are associated with cerebellar dysfunction. Mult Scler. 2009;15(7):811-7.

124. Cocozza S, Petracca M, Mormina E, et al. Cerebellar lobule atrophy and disability in progressive MS. J Neurol Neurosurg Psychiatry. 2017;88(12): $1065-72$.

125. Eshaghi A, Bodini B, Ridgway GR, et al. Temporal and spatial evolution of grey matter atrophy in primary progressive multiple sclerosis. Neuroimage. 2014;86:257-64.

126. Inglese M, Petracca M, Mormina E, et al. Cerebellar volume as imaging outcome in progressive multiple sclerosis. PLoS One. 2017;12(4):1-11.

127. Lassmann $H$, Brück $W$, Lucchinetti CF. The immunopathology of multiple sclerosis: an overview. Brain Pathol. 2007;17(2):210-8. 
128. Vercellino $M$, Masera S, Lorenzatti $M$ et al. Demyelination, inflammation, and neurodegeneration in multiple sclerosis deep gray matter. J Neuropathol Exp Neurol. 2009;68(5):489-502.

129. Ropele S, Kilsdonk ID, Wattjes MP, et al. Determinants of iron accumulation in deep grey matter of multiple sclerosis patients. Mult Scler J. 2014;20(13):1692-8.

130. Burgetova A, Dusek P, Vaneckova M, et al. Thalamic iron differentiates primary-progressive and relapsing-remitting multiple sclerosis. Am J Neuroradiol. 2017;38(6):1079-86.

131. Elkady AM, Cobzas D, Sun H, Blevins G, Wilman AH. Progressive iron accumulation across multiple sclerosis phenotypes revealed by sparse classification of deep gray matter. J Magn Reson Imaging. 2017;46(5):1464-73.

132. Schweser F, Raffaini Duarte Martins AL, Hagemeier $\mathrm{J}$, et al. Mapping of thalamic magnetic susceptibility in multiple sclerosis indicates decreasing iron with disease duration: a proposed mechanistic relationship between inflammation and oligodendrocyte vitality. Neuroimage. 2018;167:438-52.
133. Sepulcre J, Sastre-Garriga J, Cercignani M, Ingle GT, Miller DH, Thompson AJ. Regional gray matter atrophy in early primary progressive multiple sclerosis. Arch Neurol. 2006;63(8):1175.

134. Kolasinski J, Stagg CJ, Chance SA, et al. A combined post-mortem magnetic resonance imaging and quantitative histological study of multiple sclerosis pathology. Brain. 2012;135(10):2938-51.

135. Zivadinov R, Ramasamy DP, Vaneckova M, et al. Leptomeningeal contrast enhancement is associated with progression of cortical atrophy in MS: a retrospective, pilot, observational longitudinal study. Mult Scler. 2017;23(10):1336-45.

136. Azevedo CJ, Cen SY, Khadka S, et al. Thalamic atrophy in MS: an MRI marker of neurodegeneration throughout disease. Ann Neurol. 2018;83(2): 223-34.

137. Montalban X, Hauser SL, Kappos L, et al. Ocrelizumab versus placebo in primary progressive multiple sclerosis. N Engl J Med. 2017;376(3): 209-20. 